\title{
PSA Level Greater than 0.03
}

National Cancer Institute

\section{Source}

National Cancer Institute. PSA Level Greater than 0.03. NCI Thesaurus. Code C141369.

A blood concentration of prostate specific antigen greater than $0.03 \mathrm{ng} / \mathrm{mL}$. 